\title{
ATTITUDE COMPARISON OF ONE HUNGARIAN AND ONE SERBIAN TEAM'S YOUTH MALE HANDBALL PLAYERS
}

\author{
Robert Paic \\ Institute of Physical Education and Sport Science, University of Pécs, Hungary \\ Education and Society Doctoral School of Education, University of Pécs, Hungary \\ Attila Kajos \\ Business Administration Doctoral School, University of Pécs, Hungary \\ Institute of Physical Education and Sport Science, University of Pécs, Hungary \\ Milka Đukić, \\ University „Alpha“, Belgrade, Serbia \\ Darinka Korovljev \\ Faculty of Physical Education and Sport, University of Novi Sad, Serbia \\ Gyöngyvér Prisztóka \\ Institute of Physical Education and Sport Science, University of Pécs, Hungary \\ Milorad Đukić \\ Faculty of Physical Education and Sport, University of Novi Sad, Serbia
}

\begin{abstract}
The results of the Hungarian and the Serbian male handball national teams are similar on the international level; in the same time, the Hungarian club teams have more success in club competitions. However, general supposition is that the Serbian handball players are more successful and more acknowledged across the top European handball leagues. This is confirmed by numerous Serbian internationals that play at high level in Hungary and other European countries. We suppose that results of the youth national teams have considerable influence in later success rate. In this article we were searching for the influential factors behind the success of one Serbian youth team. Since there were no considerable differences in physical performance and anthropometric parameters (the Hungarian players were even taller), we assumed the main differences were in their relation and attitudes to coach and to training. In our study we support this explanation with an analysis of the attitudes to the head coach, work and physical training. Our samples were selected from one Serbian (Crvenka) and one Hungarian (Komló) youth team. For attitudes assessment a standardized PASSES scale was used (Hagger et al., 2007). The results show that the Serbian youth players have better relations with their head coach and have better stance for work and training, which might be an explanation for their better success.
\end{abstract}

Keywords: attitudes, success factors, coach, training, handball 


\section{Introduction}

In our days modern handball requires not only good technical and tactical preparation for being in a good shape but the mental-psychic factors have their significance as well. There are plenty of situations where the mentally and emotionally more stable athletes provide better performance, especially those at a younger age. Coaches have big part of the success of the team. The way of work, use of certain factors, volume and intensity are also influential factors (Đukić, 2010). The coach also has a big part in the development and maintenance of emotional stability, because it is not common that young generation have their own qualified psychologist or mental trainer. Coach who supports the athletes' self-realization also gives them the feeling of appreciation and the fact that they are valuable part of the community (De Backer, 2011). Many times coaches are not aware of the fact that their attitude affects their players' progress and decision making ability, especially because of the impact of negative criticism. Unfortunately, it happens in many sports (Walters, 2012).

Mental factors can be different in various nations' athletes' because of their different preparation, different way of approaching the game, not mentioning their different training methods. The Hungarian and Serbian senior male handball national team's efficiency is similar. (IHF ranking: Serbia 4. Hungary 5. [ihf.info 2012. may]), however there are many thoughts that the ball players from the ex-Yugoslavia are more effective, successful and admired. A number of ex-Yugoslavian players who are playing in Hungary as well as the youth men handball teams results can prove that: IHF ranking: Junior: Serbia 6. (169 points - first Germany have 198) Hungary 9. (86 points) Youth: Serbia 11. (86 points), Hungary (0 points) (ihf.info May 2012.). Moreover, a few players from Serbia played in the Hungarian national team, who were nationalized (Nikola Eklemovic, Milorad Krivokapic, Nenad Puljezevic). In our opinion the reasons of the differences have to be searched in the youth age. The aim of the study is to analyse the attitude differences comparing one Serbian and one Hungarian teams' youth men handball players' attitude towards their coaches and training. The study's principles are the works of Gombocz János - Gombocz Gábor (2006) and Hajduné László Zita - Prisztóka Gyöngyvér (u.i.) where the differences between the real and the ideal handball and basketball coaches are being analyzed as well as the players' attitudes towards coaches. Our assumption was that the Serbian athletes' attitudes to trainings are better than the Hungarian ones and that the Serbian players' relationship with their coach is better as well.

\section{Method}

The study model compares two youth (from age 14 to 18) men handball team's players $(\mathrm{n}=37)$. The Hungarian Komlói BSK $(\mathrm{n}=17)$ and the Serbian RK Crvenka $(\mathrm{n}=20)$ both had players who represented their countries in a big tournament. The two teams were chosen because they represent high quality youth systems in accordance of the country average, although at this moment their first teams competing in the second level of their national divisions. Both team's young players compete in more levels. Players from Komló have 5 trainings per week and plays league matches on the weekends, while also competing in he Hungarian Youth Cup. Players from Crvenka have 6 trainings a week and compete both in the youth league and cup. Both club's training lasts for 90 minutes, so we can conclude that both nations' players' competitions and training schedule are similar. Previously achieved results (from season 2010/2011) shows that the Serbian youth players were more successful. Crvenka finished the season $8^{\text {th }}$ while Komló was only $16^{\text {th }}$.

We enrolled data from January 2012 to May 2012. A two-part questionnaire was used from the method PASSES (The perceived autonomy support scale for exercise settings, 
Attitudes of hungarian and serbian handball players

developed by Hagger and his co-workers (2007), which studies the students' attitude to their P.E. teachers and classes. In our research we altered P.E. teachers to coaches and P.E. classes to handball trainings. During the research both the athletes' anthropometric and scholastic record were collected and recorded. The questionnaire results were divided into two groups. The first contains questions about the coaches (15 questions); while the second interests on the subject of trainings (18 questions. In the part which concerning coaches the answers were given on a 7point Likert scale where 1 meant I totally disagree and 7 meant I totally Agree; while the answers about trainings are given on a 4-point Likert scale where 1 meant I totally agree and 4 meant $I$ totally disagree. In the training questionnaire the principal question was "Why do you work hard on trainings". The reverse direction of scaling could be confusing, but we didn't want to change the original (PASSES) surveys methods. We processed the data with IBM SPSS Statistics 20 and Excel programs where we used simple mathematic-statistic (descriptive) methods and factor analysis.

\section{Results and Discussion}

After analyzing the athlete's stance to their coaches we can conclude that Serbian young players has different opinion about their coach and has more positive relation to him than the Hungarians. We can see from the Figures 1 and 2 that the average points are higher in every question related to trainer in specific fields.

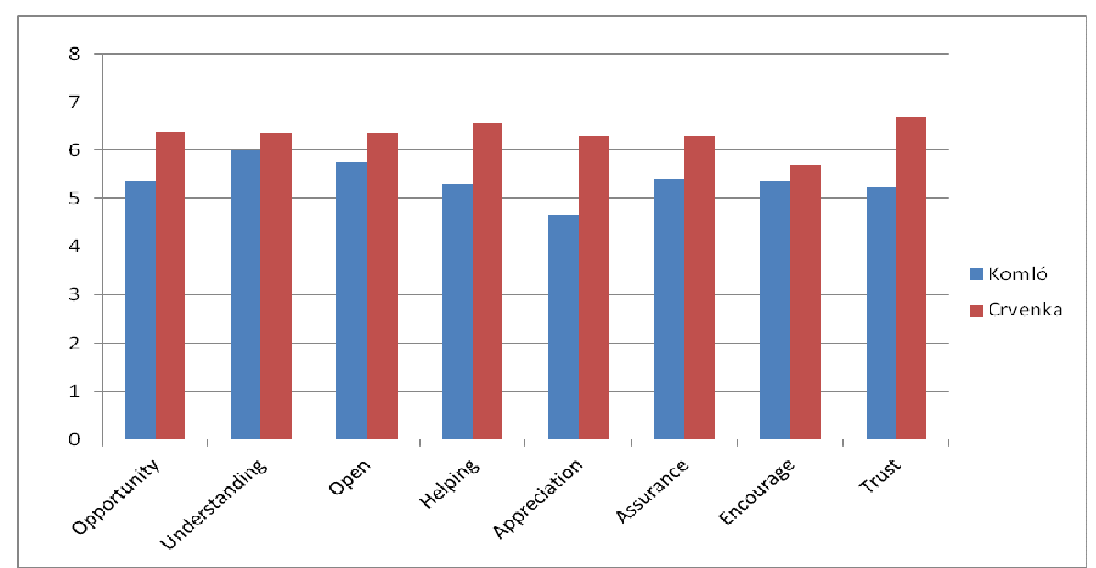

Figure 1. Average points of Hungarian and Serbian players to questions from 1 to 8

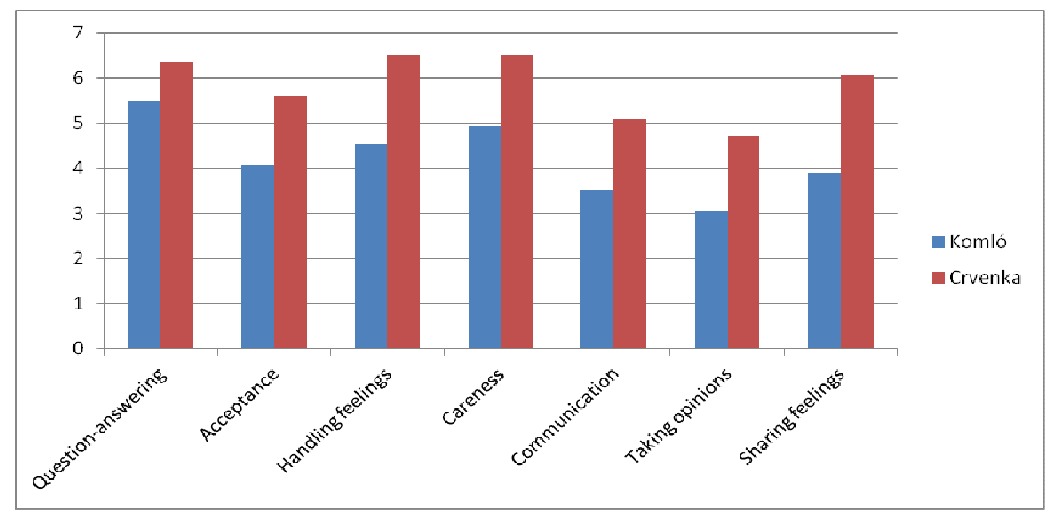

Figure 2. Average points of Hungarian and Serbian players to questions from 9 to 15 


\section{R. Paic et al.}

The most singnificant difference between Hungarian and Serbian young athletes were in fhe fields of coach appreciation, trust, acceptance and handling and sharing their feelings. The lowest results were resulted to the questions "Does your coach ask you for an opinion"and "Do you feel right the way your coach talks to you". This reflects the trainers' authoritive behavior and the lack of interactive communication. Thus we can conclude that Serbian youth players gave more points in every aspect according to the relation to their trainer. Hungarian athletes scores almost reaches the Serbians in the field of understanding and encourage.

Only three results proven insignificant when analysing the differences between the answers of Hungarian and Serbian players (using ANOVA, with $\mathrm{p}<0,05-9$ cases with $\mathrm{p}<0,01$ ). These were "Understanding", "Open" and "Encourage". All other answers showed significant differences between the youth players of the different nations.

The most conspicuous difference when analysing the answers concerning training questions, is that there is only one question out of the 18 where the average result increases 2 in case of the Serbian youngsters (which means that the given territory at least partly motives the athlete) while in case of Hungarian players' this number is 8. Moreover, among the Hungarian athletes 5 elements reach or even surpass the value of 2.7.

When concentrating on the differences of the points given to each training questions average points (using ANOVA) 15 out of the overall 18 questions $(\mathrm{p}<0.05)$ were significantly different. The Hungarian and Serbian players answers were alike on the following three questions: "Because the training is important to me" (HUN mean=1.05; SRB mean=1.05; $\mathrm{F}=0.013$; Sig.=0.909); "To be a good player" (HUN mean=1.88; SRB mean=1.95; F=0.34; Sig.=0.854) and "Because it is a good thing to practice" (HUN mean=1.82; SRB mean=1.55; $\mathrm{F}=0.766$; Sig.=0.387). In all other cases the Serbian youth players gave significantly lower grades then their Hungarian sport mates.

We can conclude from these answers that the Serbian youth handball players are more motivated in connection with their trainings (the average was 1.36 while in the Hungarian sample the average was 2.12).

The main question to ask is why these athletes coming from two different countries have different motivations? What motivates them most separately? The tables 1 and 2 present the relevant data.

Table 1.

Hungarian handball players' answers to the question ,, Why do you work hard on trainings?"

\begin{tabular}{|c|c|}
\hline Answers & Points \\
\hline 1. Because the training is important to me & 1.05 \\
\hline 2. Because I find it useful & 1.47 \\
\hline 3. Because I miss it when I don't practice & 1.58 \\
\hline 4. Because I find it enjoyable & 1.64 \\
\hline 5. To do well on the training & 1.71 \\
\hline
\end{tabular}


Table 2 .

Serbian handball players' answers to the question "Why do you work hard on trainings?"

\begin{tabular}{lc}
\hline rank $\quad$ Answers & Points \\
\hline 1. Because the training is important to me & 1.05 \\
1. Because I find it useful & 1.05 \\
3. Because I find it enjoyable & 1.10 \\
4. Because I miss it when I don't practice & 1.15 \\
5. Because I enjoy it & 1.20 \\
5. Because I have to do it on my coaches command & 1.20 \\
5. Becuse it gives me the feeling of joy and & 1.20 \\
satisfaction & 1.20 \\
5. Because it helps me in learning and developing &
\end{tabular}

It is also interesting, which factors motivate them the least. These factors are presented in table 3 and 4.

Table 3.

Hungarian handball players'answers, for the question „, Why do you work hard on trainings?”

\begin{tabular}{lc}
\hline rank $\quad$ Answers & Points \\
\hline 18. Because I will be punished if I don't practice & 3.65 \\
17. Because I will get into trouble if I don't practice & 3.23 \\
16. I am ashamed if I don't practice & 2.76 \\
14. Because it is expected from me & 2.71 \\
14. Because I feel guilty if I don't practice & 2.71 \\
\hline
\end{tabular}

Table 4.

Serbian handball players' answers, on the question ,Why do you work hard on trainings?"

\begin{tabular}{lc}
\hline rank & Answers \\
\hline 18. Because I will be punished if I don't & 2.05 \\
17. To be a good player & 1.95 \\
16. Because I am ashamed if I don't practice & 1.90 \\
15. Because it is a good thing to practice & 1.55 \\
13. Because I will get into trouble if I don't practice & 1.40 \\
13. Because it is not good when I don't practice & 1.40 \\
\hline
\end{tabular}

It is within the tables that the Hungarian athletes are motivated in only one area. Surprisingly one of the answers is positioned at the back (Hungarian's $8^{\text {th }}$, Serbian's $17^{\text {th }}$ place) "To be a good player". Originally we supposed the fact to be a great player will be one the most determining factors, but it turned out to be false in both of the nations.

Factor analysis. We could establish by analyzing the second group of questions' that all items (18) were involved into the creations of the factor groups (Table 5). The obtained results were in all areas appropriate for conditions for factor analysis. The KMO (Kaiser-Meyer-Olkin) 


\section{R. Paic et al.}

criteria was 0.658 which is considered as medium-adequate factor creating variable mixture. The Bartlet-test also had high significance level (368.219 Chi-Square distribution at 0.000 significance level).

The questions integration to factors was confirmed by certain variables communalities (the lowest communality was 0.677 which is beyond the most strict 0.5 level) as well the determination of factor analysis with maximum likelihood method index number (59.549 ChiSquare rate at 0.492 significance). Maximum likelihood tests have shown the main component analysis and the Kaiser-criteria (factors eigenvalue min. 1) approves 6 equivalent factors (the significance level was 0.267 with 5 factors). The factors explain $76.81 \%$ of variance, so we can accept them as good consideration. By all these facts we can separate 6 different factors.

Table 5.

Isolated factors and corresponding variables

\begin{tabular}{ll}
\hline \multicolumn{1}{c}{ Name of the factor } & \multicolumn{1}{c}{ Variables } \\
\hline Because I enjoy the training. \\
Because the training is useful. \\
Because I want to do well on the training. \\
Because it is expected from me.
\end{tabular}

The comparison of the Hungarian and the Serbian athletes' scores on each factor is shown in the table 6. 
Attitudes of hungarian and serbian handball players

Table 6.

Comparison of Serbian and Hungarian players average points given to factors

\begin{tabular}{lccr}
\hline & Hungarian & Serbian & Difference \\
\hline Demonstration/Self-respect & 1.92 & 1.20 & $0.72^{*}$ \\
Autority / Avoiding conflicts & 3.295 & 1.725 & $1.57^{* *}$ \\
Self-calming/ Urge & 2.23 & 1.28 & $0.95^{* *}$ \\
Correspondence & 1.89 & 1.31 & 0.58 \\
(Desire to) Develop & 1.96 & 1.20 & $0.76^{* *}$ \\
Self-expression & 1.85 & 1.75 & 0.10 \\
\hline
\end{tabular}

* means significant difference (ANOVA) with $\mathrm{p}<0.1$

$1 * *$ means significant difference with $\mathrm{p}<0.05$

We can read from the table above that the Serbian players' motivation is more individualistic. In the centre of their motivation is effectiveness and to progress. On the other hand, Hungarian players' motivation is to satisfy their coaches and themselves. We must state that the strongest motivational aspects among Hungarian youth athletes stays below Serbian's lowest ones.

When analysing the significance of differences, we find that the factors concluding the previously mentioned not significantly different variables are significantly different as well. Except for Demonstration/Self respect, which contains "Because I enjoy training", but significant difference at this factor is only valid on a $90 \%$ significance rate. Altogether we can conclude that the Serbian young players' motivation in the trainings is way better, no matter what kind of motivations they have. The next important question would be the research of the background motivation.

We have found interesting results after collecting the anthropometric parameters of the young handball players. Average height of the Hungarian players is $184.5 \mathrm{~cm}$ while it is 181.8 $\mathrm{cm}$ in case of the Serbians. Average weight was $75.2 \mathrm{~kg}$ at Komló and $76.6 \mathrm{~kg}$ at Crvenka. Scholastic record was better among the Serbian young athletes (average 3.75 to 3.07 among Hungarian athletes).

As for the limitations of the study it is important to mention that this research can be regarded only as a "pilot" study and we cannot conclude anything precisely. The main goal of the research was to test the validity of the questionnaire, and that was the reason of working with small sample size and with players only from second division. Besides that, the results are provoking and showing the differences between two countries' youth athletes. We must emphasize that the differences are not (or not only) in the technical abilities but in the varieties of attitude.

Serbian young handball players' (from Crvenka) attitudes towards their coaches differ from their Hungarian (from Komló) sport mates, especially in the area of trust, handling their feelings and admiration. This means that Serbian youth athletes are more open, have more confidence toward their coaches, which makes the opportunity to be much more effective and all in all successful. The lower points given to coaches on the area of communication, which is similar to Walters and co-workers' (2012) research results among male baseball coaches made more negative comments than female trainers. It is very important for coaches to know the constructive and destructive power of their communication skills and efforts. Their methods can result a higher but also much lower performance. In studies of Gombocz and Gombocz (2006) 


\section{R. Paic et al.}

and Hajduné László and Prisztóka Gyöngyvér (in press) we can realize the differences between ideal and real coach image, especially in the field of authority. The ideal coach is more reliable and communicative than we experience is the real world. Both countries players work hard on their trainings because they think that handball is important, useful, enjoyable and they all strive to become a great player. Surprisingly, over their more individualistic motivations the expectation from the coach and the avoidance of punishment is has stronger motivating power among Serbian handball players then Hungarians. Finally, the stance to training is way more positive among Serbian athletes, which can be one of the reasons of a better overall performance.

\section{References}

De Backer M., Boen F., Ceux T., De Cuyper B., Høigaard R., Callens F., Fransen K., \& Vande Broek G. (2011). Do perceived justice and need support of the coach predict team identification and cohesion? Testing their relative importance among top volleyball and handball players in Belgium and Norway. Psychology of Sport and Exercise,12, 192-201.

Đukić, M. (2010). Rukomet [Handball]. Novi Sad: Budućnost.

Gombocz, J., \& Gombocz, G. (2006). Opinion of young athletes of their trainer: Real and ideal image of trainers among basketball players from age 14 to 16. Kalokagathia, 1-2, 76-85.

Hagger, M. S., Chatzisarantis, N. L. D., Hein, V., Pihu, M., Soós, I., \& Karsai, I. (2007). The perceived autonomy support scale for exercise settings (PASSES): Development, validity, and cross-cultural invariance in young people. Psychology of Sport and Exercise, 8, 632653.

Hajduné László, Z., \& Prisztóka, G. (in press). Image of trainer: aspect of young handball players. Magyar Sporttudományi Szemle.

Walters, S. R., Schluter P. J., Oldman A. R. H., Thomson, R. W., \& Payne, D. (2012). The sideline behaviour of coaches at children's team sports games. Psychology of Sport and Exercise, 13, 208-215.

Rankings on International Handball Federation's website (www.ihf.info)

Rankings on European Handball Federation's website (www.eurohandball.com) 